\section{Desafíos para el Sistema de Salud con la reciente promulgación de la Ley 21.303 que otorga pleno reconocimiento a la Lengua de Señas Chilena}

\section{Challenges for the Health System with the recent enactment of Law 21,303 that grants full recognition to the Chilean Sign Language}

\section{Señor Editor,}

La recién promulgada Ley 21.303 que otorga pleno reconocimiento a la Lengua de Señas Chilena $(2021)^{1}$ establece nuevos desafíos para el Sistema de Salud y su relación con las personas Sordas. A través de la presente carta quisiera ilustrar alguno de estos desafíos.

Para la medicina, la discapacidad auditiva es un déficit sensorial que afecta la capacidad total o parcial de percibir sonidos ya sea por alteración en el oído interno o en la vía nerviosa ${ }^{2}$. Para el ámbito de la salud, la discapacidad auditiva se focaliza en los órganos físicos y en el sentido auditivo mismo determinando así la funcionalidad de la persona.

Por otra parte, la Comunidad de las Personas Sordas ha intentado desmarcarse de dicha definición, avalados en la Convención Internacional de los Derechos de las Personas con Discapacidad que, en su artículo 30 , dispone el reconocimiento a la identidad cultural y lingüística de las Personas Sordas ${ }^{3}$. Esto implica ser reconocidos como una minoría lingüística que tiene elementos en común que les conforman como una cultura ${ }^{4}$. Estos elementos son el uso de la Lengua de Señas, el participar de la comunidad de personas Sordas $\mathrm{y}$ el ser eminentemente visuales.

En Chile, La Ley 21.303 de Reconocimiento de la Lengua de Señas Chilena (2021), en su artículo único establece el estatuto natural, originario y patrimonial de la Lengua de Señas como un elemento oficial de la cultura de las personas Sordas; reconociéndose así la obligación de promover y respetar sus derechos culturales en el acceso a servicios públicos y privados de salud.

En ese sentido, el sistema de salud en general, enfrenta nuevos desafíos en su relación con las personas Sordas. Estos desafíos tienen relación con Accesibilidad a la Cultura Sorda, Profesionales, Recursos Tecnológicos y Orientación a las Familias.

Entender a las personas Sordas como cultura y no como déficit exige una relación diferente. En ese sentido, los Sistemas de Salud deberán reconocer el carácter visual de la persona Sorda, su uso de la Lengua de Señas y así también la diversidad de formas de comunicación que utilizan sus integrantes (lectura labial, español escrito, niveles de Lengua de Señas Chilena).

Por tanto, la información que se entrega a los usuarios, debe estar disponible en Lengua de Señas Chilena.
Esta información no solo es la relativa a temas administrativos, sino también a los procedimientos médicos y de salud del paciente.

Resulta importante que la información sobre el estado de Salud se entregue con detalle al paciente Sordo en su lengua oficial, especialmente cuando se trata de temas relacionados a enfermedades crónicas, embarazos, enfermedades de transmisión sexual o cuando el cuerpo deba ser expuesto. Hasta ahora esa información es entregada a familiares o amigos que acompañan a las personas Sordas para facilitar la comunicación.

Para Accesibilizar la información a las personas Sordas existen expertos que conocen la Lengua de Señas: Intérpretes en Lengua de Señas, Mediadores Sordos y Facilitadores de la Lengua de Señas.

Los Intérpretes en Lengua de Señas transmiten información de manera simultánea entre profesional y paciente. El Intérprete recoge el mensaje en español y lo interpreta en Lengua de Señas y viceversa. Los facilitadores de la Lengua de Señas tienen una función similar, con la diferencia que pueden detenerse a explicar el contexto o palabras que la persona Sorda puede no conocer. Finalmente el Mediador Sordo es una persona Sorda que actúa como intermediario entre el Intérprete o Facilitador y la Persona Sorda, cuando la Lengua de Señas es de carácter informal.

La presencia de estos expertos en Salud exigirá revisar los protocolos de devolución de información, especialmente en situaciones críticas de resguardo de la privacidad y dignidad del paciente.

La relación con usuarios Sordos implica facilitar el acceso a los medios tradicionales de comunicación basados en la audición, tales como la llamada telefónica, los llamados a viva voz y la comunicación oral. En ese sentido recursos que ayudan a una mejor atención a la comunidad sorda son las videollamadas, pantallas de aviso y Aplicaciones para explicar mediante imágenes $\mathrm{o}$ videos procedimientos médicos.

De igual forma, reconocer a la cultura Sorda como una minoría lingüística, implica que los sistemas de Salud que detectan hipoacusia modifiquen sus proto$\operatorname{colos}^{5,6}$. Las familias de niños y niñas Sordos, además de recibir información sobre implantes, cirugías y procedimientos médicos, necesitan recibir orientación respecto del uso de la Lengua de Señas y de la Comunidad de Personas Sordas. Esto es de gran importancia para que los Sordos y Sordas recién nacidos tengan acceso a su lengua oficial, evitando así retraso en la adquisición del lenguaje que experimentan los niños y niñas Sordos que esperan intervenciones y terapias para aprender a hablar? .

Los desafíos son numerosos, difundir a todo el personal de salud una nueva forma de relación con un grupo cultural distinto, así como la incorporación de nuevas personas y el progresivo aprendizaje de la Lengua de Señas por parte de la comunidad de salud, 
obligarán a revisar los procedimientos y la forma de relacionarse con la comunidad de personas Sordas.

\section{Gabriel Sánchez Díaz ${ }^{1,2,3}$, Jorge Eduardo Alfaro Urrutia ${ }^{4,5}$ \\ ${ }^{1}$ Director Consejo Nacional de Educación por las personas Sordas de Chile, Fesorchile. \\ ${ }^{2}$ Vicepresidente Club Cultural de Sordos de Puerto Montt, Chile. \\ ${ }^{3}$ Coordinador de Educación de Estudiantes Sordos, DAEM, Puerto Montt. \\ ${ }^{4}$ Doctor en Educación. \\ ${ }^{5}$ Coordinador del Programa de Integración Escolar DAEM Puerto Montt, Chile.}

\section{Referencias}

1. Ley 21.303 [Internet]. Ministerio de Salud - Gobierno de Chile. [cited 2021 Feb 03]. Available from https://www.bcn. $\mathrm{cl} /$ leychile/navegar?idNorma $=1154963$.

2. Albertz N, Cardemil F, Rahal M, Mansilla F, Cárdenas R, Zitko P. Programa de Tamizaje Universal e intervención precoz (PTUIP) en hipoacusia sensorioneural bilateral congénita. Tarea pendiente desde la perspectiva de políticas públicas de salud en Chile. Rev Med Chile 2013; 141: 1057 63.

3. ONU. [Internet] Convención sobre los derechos de las personas con discapacidad. [cited $2021 \mathrm{Feb}$ 03]. Available from https://www.un.org/esa/socdev/enable/documents/ tccoonvs.pdf.

4. Ladd P. Understanding deaf culture: In search of deafhood. Bristol. Multilingual Matters. 2011.

5. MINSAL. [Internet]. Hipoacusia neurosensorial bilateral del prematuro. 2010. [cited $2021 \mathrm{Feb} 03$ ] Available from https://www.minsal.cl/portal/url/item/721fc45c97379016e04001011f0113bf.pdf.

6. MINSAL. [Internet]. Tratamiento de Hipoacusia moderada en menores de 2 años. 2013. [cited 2021 Feb 03]. Available from https://www.minsal.cl/portal/url/item/de429df07a91ca3ce040010165017ea0.pdf.

7. Glickman N, Hall W. Editors. Language deprivation and deaf mental health. New York. Routledge. 2019.

Correspondencia a:

Gabriel Sánchez Díaz

DAEM, Puerto Montt, Chile.

gabodeaf@gmail.com

\section{El desarrollo de la biología celular en Chile: Aportes del Dr. Juan de Dios Vial Correa (1925-2020)}

\section{The development of cell biology in Chile: Contributions of Prof. Juan de Dios Vial Correa, M.D. (1925-2020)}

\section{Señor Editor,}

El interesante artículo de los doctores Sabaj y Osorio $^{1}$ es fuente de historiografía científica relevante sobre los inicios de la biología celular chilena. Esta historia se completa con quienes le fueron dando impulso y desarrollo a dicha disciplina. Al respecto, el 17 de agosto de 2020 la ciencia chilena ha sufrido una profunda pérdida con la partida del Dr. Juan de Dios Vial Correa (Figura 1), Rector Emérito de la Pontificia Universidad Católica de Chile y Miembro Supernumerario de la Academia Chilena de Ciencias. Esta Carta al Editor tiene por objetivo destacar la obra del Dr. Vial como figura clave en el desarrollo de la biología celular y la biomedicina chilena.

Juan de Dios Vial Correa (Santiago, 18 de mayo de 1925) cuando niño disfrutaba observar con un microscopio de bolsillo los protozoos de los charcos ${ }^{2}$, afición observacional que podría haber sido un indicio de su futuro ${ }^{2}$. Ingresó a estudiar Medicina en la Pontificia Universidad Católica de Chile luego de haber descartado Agronomía, Ingeniería y Derecho, que eran sugeridas por algunos familiares ${ }^{2}$. Durante su tercer año de estudios, habiendo efectuado unas preparaciones histológicas, quedó maravillado por la estructura del aparato de Golgi, más tarde se interesó en morfología, anatomía patológica y, finalmente, después de titularse de Médico Cirujano (1949), viajó a estudiar neurohistología al Instituto Cajal en España ${ }^{2}$. Finalizada esta estadía, viajó a EE.UU. a perfeccionarse en el laboratorio del Dr. Edward Dempsey (1911-1975), académico del Departamento de Anatomía de la Universidad de Washington en San Luis, Misuri. Posteriormente, partió en 1951 a Nueva York a estudiar bajo la dirección del Dr. Keith R. Porter (1912-1997), investigador del Instituto Rockefeller ${ }^{2}$. Fue en el laboratorio de este connotado biólogo citólogo que la investigación mediante microscopía electrónica generó profundo impacto en el Dr. Vial pues los nuevos hallazgos estaban cambiando rápidamente los paradigmas biológicos: la citología estaba pasando a un nuevo estadio que, mediante la microscopía electrónica, comenzaba a conciliar la bioquímica 